\title{
Tropical Journal of Pathology and \\ Microbiology

\section{Small Bites - Big Threats: Prevalence of scrub typhus among the pediatric population in a rural tertiary care hospital in South India}

\author{
Kumar B R. ${ }^{1}$, Anupriya A. ${ }^{2 *}$, Uma A. ${ }^{3}$, Prabhusaran N. ${ }^{4}$ \\ DOI: https://doi.org/10.17511/jopm.2020.i04.04
}

1 Raj Kumar B, 3rd Year MBBS Student, Department of Microbiology, Trichy SRM Medical College Hospital and Research Centre, Tiruchirapalli, Tamil Nadu, India.

2* Anupriya A., Associate Professor, Department of Microbiology, Trichy SRM Medical College Hospital and Research Centre, Tiruchirapalli, Tamil Nadu, India.

3 Uma A., Professor and Head of Department, Department of Microbiology, Trichy SRM Medical College Hospital and Research Centre, Tiruchirapalli, Tamil Nadu, India.

4 Prabhusaran N., Associate Professor, Department of Microbiology, Trichy SRM Medical College Hospital and Research Centre, Tiruchirapalli, Tamil Nadu, India.

Background: It is an acute, febrile, exanthematous illness with a high fatality rate. Scrub typhus is underdiagnosed in India due to its non-specific clinical presentation, limited awareness, and low index of suspicion among clinicians and lack of diagnostic facilities. Objective: This study was carried out to know the seroprevalence of scrub typhus in clinically suspected children and to compare a rapid test which is a simple and economic test with IgM ELISA for the diagnosis of scrub typhus. Methods: This cross-sectional analytical study was conducted from a period of three months. The study population comprised mainly 140 young children attending Pediatric OP and in patients admitted to a tertiary care teaching hospital with fever and related symptoms. A serum sample was tested for Weil Felix reaction, IgM ELISA, and rapid card test. Results: The mean age group of the study population is 7 to 9 years, of which seven cases were positive. The major predisposing factor for scrub typhus infection was vegetation around houses. The sensitivity and specificity of both card test and IgM ELISA was $100 \%$. Conclusion: In this study, $5 \%$ of febrile children were positive for scrub typhus. Leptospirosis, Dengue, and Typhoid were the common coinfections found in scrub typhus, positive children. Scrub typhus should be included in the differential diagnosis of fever of unknown origin in children.

Keywords: Febrile children, Orientia tsutsugamushi, Scrub typhus

Corresponding Author

Anupriya A., Associate Professor, Department of Microbiology, Trichy SRM Medical College Hospital and Research Centre, Tiruchirapalli, Tamil Nadu, India.

Email: priyamanivelan@gmail.com

\section{How to Cite this Article}

Kumar BR, Anupriya A, Uma A, Prabhusaran N. Small Bites - Big Threats: Prevalence of scrub typhus among the pediatric population in a rural tertiary care hospital in South India. Trop J Pathol Microbiol. 2020;6(4):292-297.

Available From

https://pathology.medresearch.in/index.php/jopm/ar ticle/view/432

\section{To Browse}

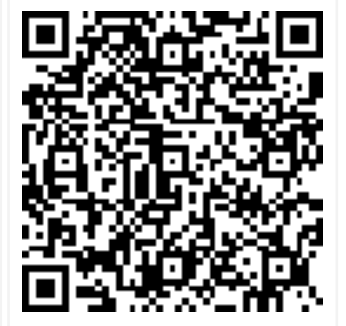

Manuscript Received 10-03-2020

Conflict of Interest No
Review Round 1 20-03-2020

Funding

Review Round 2
24-03-2020
Ethical Approval
Yes

Review Round 2

Yes
Review Round 3

Plagiarism X-checker $18 \%$
Accepted 30-03-2020

Note

(c) 2020 by Raj Kumar B, Anupriya A., Uma A., Prabhusaran N. and Published by Siddharth Health Research and Social Welfare Society. This is an Open Access article licensed under a Creative Commons Attribution 4.0 International License https://creativecommons.org/licenses/by/4.0/ unported [CC BY 4.0]. 


\section{Introduction}

Scrub typhus, a mite borne Rickettsial disease caused by the Orientia tsutsugamushi, was once widely prevalent in the Tsutsugamushi triangle in the East Pacific region [1]. It is an acute, febrile, exanthematous illness with a high fatality rate. According to the World Health Organization, "Scrub typhus is probably one of the most under-diagnosed and under-reported febrile illnesses requiring hospitalization ?[2]. Scrub typhus accounts for up to $23 \%$ of all febrile episodes, with an estimated 1 million cases occurring annually, in endemic areas.

Human beings get infected accidentally when they encroach upon mite-infested rural and suburban areas. It is often acquired during recreational, occupational, or agricultural exposure because crop fields are an important reservoir for transmission. It was considered a lethal disease in the pre-antibiotic era and continues to be a public health problem in South Asian and Western Pacific regions.

Four elements are essential to maintain $O$. tsutsugamushi in nature. Trombiculid mites, small mammals like the field, mice, rats, secondary scrub vegetations, and wet season (when mite lays eggs) [3].

The clinical spectrum of scrub typhus varies from mild to moderate severity. Acute fever is the most common manifestation later accompanied by headache, myalgia, and cough [4]. Eschar is a characteristic skin lesion usually observed in most of the scrub typhus patients. Severe complications include prominent encephalitis, interstitial pneumonia, and ARDS, circulatory collapse with hemorrhagic features. Mortality may be as high as 35 to $60 \%$ if diagnosis or appropriate therapy is delayed [5].

Several tests are available with their own advantages and limitations. Weil-Felix test is being the cheapest and easily available, shares antigens with other bacteria (members of Enterobacteriaceae). IgM ELISA has been evaluated and found to be satisfactory in diagnosis. Rapid test (Immunochromatography) which is economic and single tests can be carried out.

Scrub typhus is under-diagnosed in India due to its non-specific clinical presentation, limited awareness, and low index of suspicion among clinicians and lack of diagnostic facilities. Once diagnosed, treatment with Doxycycline is affordable and successful with a
Dramatic clinical response within 48 hours. In children, treatment with azithromycin for 3 days is recommended [3].

This study was carried out to know the seroprevalence of scrub typhus in clinically suspected children and to compare a rapid test which is a simple, and economic test with IgM ELISA for the diagnosis of scrub typhus.

\section{Material and Methods}

The setting of the study- The present study was conducted in a tertiary care teaching hospital to all young children attending Paediatric $\mathrm{OP}$ and in patients.

Duration and type of study- The present crosssectional analytical study was conducted from the period of May to June 2019.

Sampling methods- Universal sampling was done and all children presenting with fever and related symptoms were included. There were a total of 140 children presenting with fever and related symptoms.

Sample size calculation: -The sample size was calculated from pre-existing studies in the literature with a prevalence rate of $23 \%$ in adults in the Pondicherry [3].

Inclusion criteria: All children presenting with acute febrile illness due to infectious etiology

Exclusion criteria: Children presenting with fever due to metabolic causes or other non-infectious etiology were excluded.

Data collection procedure- A structured proforma was utilized for the current study. The details like age, place where the child is residing, socioeconomic status, educational qualification of the mother, source of drinking water, history of any vector bites, rodents near the houses, history regarding vaccination status of the child were obtained.

Under strict aseptic precautions, 3 to $5 \mathrm{ml}$ blood was collected from children using a sterile syringe. Complete hemogram, erythrocyte sedimentation rate, C-reactive protein (CRP), liver function tests, and renal function tests were also performed. In all cases, a peripheral smear and/or QBC test was performed to exclude malaria and Widal was put up to rule out the enteric fever. In cases of negative for malaria and enteric fever, the presence of leptospiral 
Dengue, chikungunya infection was investigated by IgM ELISA for Leptospira, IgM antibody, and NS1 antigen ELISA (Panbio) for dengue and IgM ELISA (Panbio) for Chikungunya.

Finally, after all these investigations the serum sample was tested for Weil Felix reaction and scrub typhus IgM ELISA using the INBIOS kit. A rapid card test was done in addition to this. A single titer of $\geq$ $1: 160$ or a four-fold rise in titer from two consecutive samples submitted a week apart is considered significant Rapid card test by SD Bioline Tsutsugamushi, rapid qualitative test for the detection of antibodies (IgG, IgM, and IgA) to Orientia tsutsugamushi was used.

Ethical consideration and permission- The purpose of the study was explained to the parents of the children presenting with fever and written informed consent was obtained before enrolling in the study. Institutional Ethics Clearance was obtained before starting the study (Ref. No: 636/ TSRMMCH and RC/ ME-1/ 2019 - IEC No: 006 dated 17.07.2019).

Statistical analysis- The cases which were found to be positive with scrub typhus was noted. Coinfections are quite common, so if the child tests positive for either WIDAL or leptospirosis was taken and analyzed. The cases were evaluated with their habitat and any conclusive finding was noted. Statistical analysis was done using version Epi info version 7.2 Statistical software for windows.

\section{Results}

All the acute febrile illness of pediatric cases attending the hospital was taken into account. The current study observed about 140 cases. The age and gender analysis of the patients included in this study were depicted in Table 1.

Table-1: Age-wise prevalence of the study population.

\begin{tabular}{|l|l|l|l|}
\hline Age (in years) & \multicolumn{1}{|c|}{ Male } & Female & \multicolumn{1}{|c|}{ Number of cases $(\mathbf{n}=140)$} \\
\hline 4 to 6 & 24 & 14 & $38(27.1)$ \\
\hline 7 to 9 & 38 & 17 & $55(39.3)$ \\
\hline 10 to 12 & 25 & 22 & $47(33.6)$ \\
\hline & $87(62.1)$ & $53(37.9)$ & $140(100)$ \\
\hline
\end{tabular}

[Figure in parenthesis denoted percentages]

Gender wise analysis of the study population was recorded as 62.1 and $37.9 \%$ among males and females respectively. Of the 7 scrub typhus positive cases, 4 were male and 3 were female children.
The major factors of the predisposition of scrub typhus were analyzed and among 7 positive cases, $42.8 \%$ had vegetation around houses, $28.5 \%$ had the habit of frequent forest visiting, $28.5 \%$ used to defecate at open fields and $14.2 \%$ practice poor personal hygiene (Table 2).

Table 2: Predisposing factors to scrub typhus $(n=7)$.

\begin{tabular}{|l|l|}
\hline \multicolumn{1}{|c|}{ Predisposing factors } & \multicolumn{1}{c|}{ Number of patients $(\mathrm{n}=\mathbf{7})$} \\
\hline Vegetation around houses & $3(42.8 \%)$ \\
\hline Open field defaecation & $2(28.5 \%)$ \\
\hline Forest visiting & $2(28.5 \%)$ \\
\hline Poor personal hygiene & $1(14.2 \%)$ \\
\hline
\end{tabular}

The laboratory investigations of the positive scrub typhus were analyzed thereby leucocytosis, anemia was found among 5 and 2 cases respectively. Elevated transaminase levels were found among one child; increased bilirubin and urea/ creatinine also found among one case each and the detailed laboratory investigations are impregnated in table 3.

Table 3: Laboratory investigations of positive cases $(n=7)$.

\begin{tabular}{|l|l|}
\hline \multicolumn{1}{|c|}{ Lab investigations } & \multicolumn{1}{|c|}{$\begin{array}{c}\text { Number of cases } \\
(\mathbf{n = 7})\end{array}$} \\
\hline Total leucocyte count $>11,000 /$ cu.mm & $5(71.4 \%)$ \\
\hline Anaemia (haemoglobin<10 g/dl) & $2(28.5 \%)$ \\
\hline Elevated transaminase levels (normal 40/56 I.U) & $1(14.2 \%)$ \\
\hline Increased bilirubin (normal 0.3-0.8 mg/dl) & $1(14.2 \%)$ \\
\hline $\begin{array}{l}\text { Increased urea/creatinine (normal 60/0.6-1.2 } \\
\mathrm{mg} / \mathrm{dl})\end{array}$ & $1(14.2 \%)$ \\
\hline
\end{tabular}

Other serological investigations were done. Of the 140 cases, WIDAL, ASO, CRP, leptospirosis, malaria, and dengue were found to be positive in $24,16,39$, 4,2 , and 2 respectively (Table 4 ).

Table-4: Profile of serological investigations of the study population.

\begin{tabular}{|l|l|l|}
\hline Investigations & \multicolumn{1}{|c|}{$\begin{array}{c}\text { Number of cases positive } \\
(\mathbf{n = 1 4 0 )}\end{array}$} & $\begin{array}{l}\text { Scrub typhus positive } \\
(\mathbf{n}=\mathbf{7})\end{array}$ \\
\hline $\begin{array}{l}\text { C - reactive } \\
\text { protein }\end{array}$ & $39(27.8)$ & $2(28.6)$ \\
\hline ASO & $16(11.4)$ & - \\
\hline typhoid & $24(17.1)$ & $1(14.2)$ \\
\hline Malaria & $2(1.4)$ & - \\
\hline Dengue & $2(1.4)$ & $1(14.2)$ \\
\hline Leptospira & $4(2.8)$ & $1(14.2)$ \\
\hline Scrub typhus & $7(5)$ & $7(100)$ \\
\hline Non-reactive & $49(35)$ & - \\
\hline
\end{tabular}

[Figure in parenthesis denoted percentages] 
Weil Felix test gave more false positive and false negative results in this study; sensitivity and specificity of the Weil-Felix test were to be found as $57.1 \%$ and $85.7 \%$ respectively. This implies that Weil-Felix is not a reliable diagnostic test when compared with the card test and IgM ELISA results.

The sensitivity and specificity related to the tests done for screening scrub typhus were done and tabulated (Table 5). Co-infections were found with Leptospira $(14.2 \%)$, dengue $(14.2 \%)$ and typhoid (14.2\%) (Table 6).

Hence, the prevalence of scrub typhus with other co-infections is common.

Table 5: Screening and diagnostic tests for scrub typhus and results in the study population $(n=140)$.

\begin{tabular}{|l|l|l|l|l|}
\hline Tests & $\begin{array}{c}\text { Number of } \\
\text { cases positive } \\
\text { for the test }\end{array}$ & $\begin{array}{c}\text { Number of cases } \\
\text { negative for the } \\
\text { test }\end{array}$ & $\begin{array}{c}\text { The } \\
\text { sensitivity of } \\
\text { the test (\%) }\end{array}$ & $\begin{array}{c}\text { The } \\
\text { specificity of } \\
\text { the test (\%) }\end{array}$ \\
\hline $\begin{array}{l}\text { Weil } \\
\text { Felix } \\
\text { test }\end{array}$ & 28 & 112 & 57.1 & 85.7 \\
\hline $\begin{array}{l}\text { Card } \\
\text { test }\end{array}$ & 7 & 133 & 100 & 100 \\
\hline $\begin{array}{l}\text { IgM } \\
\text { ELISA }\end{array}$ & 7 & 133 & 100 & 100 \\
\hline
\end{tabular}

Table 6: Comparison of test results of scrub typhus positive cases $(n=7)$.

\begin{tabular}{|l|l|l|}
\hline \multicolumn{1}{|c|}{ Tests } & \multicolumn{1}{|c|}{$\begin{array}{c}\text { Number of cases positive } \\
\text { for the test }\end{array}$} & $\begin{array}{l}\text { Number of cases negative } \\
\text { for the test }\end{array}$ \\
\hline $\begin{array}{l}\text { Weil Felix } \\
\text { test }\end{array}$ & $4(57.1)$ & $3(42.9)$ \\
\hline Card test & $7(100)$ & - \\
\hline IgM ELISA $7(100)$ & - \\
\hline
\end{tabular}

[Figure in parenthesis denoted percentages]

\section{Discussion}

Scrub typhus, a long-forgotten and neglected infectious disease, with no licensed vaccines is undoubtedly a reemerging disease. With improvements in approaches to estimating the burden of febrile illnesses, it is important to reevaluate the burden of scrub typhus. A study done in Ludhiana in 2014 reported that out of 772 fever patients, $12.7 \%$ positive for scrub typhus [5].

Another study done in India [6] observed that 24\% of patients presenting with unexplained febrile illness had scrub typhus. A study done in Goa during 2012 found that $34 \%$ of fever cases [7] were
Positive for IgM antibodies against $O$. tsutsugamushi.

The mean age group of the study population was 7 to 9 years $(39.3 \%)$, which is similar reported [8]. Most of the study participants resided in the rural area $(58.6 \%)$, thereby the proximity to mite friendly surroundings appears to be more. Studies have shown that rodents carrying the mites are transmitting the disease in the urban locales in India $[9,10]$. Urbanization, contaminated environment, and rodent population had made it suitable for the transmission of the disease in the urban setting.

The abnormalities in cell counts, and liver and renal functions in the present study were consistent with those reported in other studies $[11,12]$. Of the 140 cases, $7(5 \%)$ tested positive for scrub typhus in card test and IgM ELISA. Scrub typhus was diagnosed by Weil-Felix, card test, and IgM ELISA where sensitivity and specificity of the Weil-Felix test were 57.1 and $87.5 \%$ respectively.

The sensitivity and specificity of the card test and ELISA was $100 \%$. An earlier study conducted in Thailand using SD Bioline ICT had reported sensitivity and specificity to be 66.7 and $98.4 \%$, respectively [13]. On the contrary, it was reported that higher sensitivity $(72.6 \%)$ of SD Bioline ICT in the Korean population [14].

Another ICT, ImmuneMed RDT was found to be more sensitive $(98.6 \%)$ than SD Bioline RDT $(84.8 \%)$ in the Korean population [15]. A comparative study to determine the sensitivity was found as 44 and $87 \%$ with Weil-Felix test and IgM ELISA respectively [16].

Of the scrub typhus positive cases, $14.2 \%$ of cases were co-infected with either Leptospira or dengue or typhoid. A study done in Odisha [17] supported the fact where $36.2 \%$ of cases were positive for malaria, dengue, or chikungunya. Similarly, a study done in Arunachal Pradesh [18], confirms the coinfection rate of scrub typhus and Leptospira being $25 \%$. This may be due to greater exposure to mites/ mammals, in the field and to the rodents during household activities at home.

\section{Limitations of the study}

- The study is a single centered.

- A seasonal variation could not be studied.

- Entire population (Only Paediatric population) was not included; thereby full prevalence can't be detected 


\section{Conclusion}

The study recommends that scrub typhus should be included in the differential diagnosis of fever of unknown origin along with leptospirosis and dengue fever which are other endemic diseases in this region, which will help in proper diagnosis, timely and adequate treatment and avoidance of the complications which are associated with high mortality.

\section{What does the study add to the existing knowledge?}

The study recommends that scrub typhus should be included in the differential diagnosis of fever of unknown origin along with leptospirosis and dengue fever which are other endemic diseases in this region, which will help in proper diagnosis, timely and adequate treatment and avoidance of the complications which are associated with high mortality.

\section{Author's contribution}

RajKumar B.: Planning the study,

Dr. Anupriya A.: Data collection and analysis

Dr. Uma A.: Statistical analysis

Dr. Prabhusaran N.: Manuscript preparation

\section{Reference}

01. Viswanathan S, Muthu V, Iqbal N, Remalayam B, George T. Scrub typhus meningitis in South India - A retrospective study. PLoS One. 2013;8(6)e66595.

doi:[Article:https://dx.doi.org/10.1371\%2Fjournal. pone.0066595][Crossref]

02. Mittal V, Gupta N, Bhattacharya D, Kumar K, Ichhpujani RL, Singh S, Chhabra M, Rana UVS. Serological evidence of rickettsial infections in Delhi. Indian J Med Res. 2012;135(4)538-541. Available from:[Article:http://www.ijmr.org.in/text. asp?2012/135/4/538/96756][Crossref]

03. Palanivel S, Nedunchelian K, Poovazhagi V, Raghunadan R, Ramachandran P. Clinical profile of Scrub typhus in children. Indian J Pediatr. 2012;79(11)1459-1462.

doi: [Article:https://doi.org/10.1007/s12098-0120721-0][Crossref]
04. Oberoi A, Varghese SR. Scrub typhus - an emerging entity; A study from a tertiary care hospital in North India. Ind $\mathrm{J}$ Publ HIth. 2014;58(4)281-283.

Available from: [Article:http://www.ijph.in/text.asp? 2014/58/4/281/146299][Crossref]

05. Roopa KS, Karthika K, Sugumar M, Bammigatti C, Shamanna SB, Harish BN. Serodiagnosis of Scrub Typhus at a Tertiary Care Hospital from Southern India. J Clin Diagn Res. 2015;9(11)57 . doi:

[Article:https://dx.doi.org/10.7860\%2F]CDR\%2F201 5\%2F15871.6759][Crossref]

06. Ramyasree A, Kalawat U, Rani ND, Chaudhury A. Seroprevalence of scrub typhus at a tertiary care hospital in Andhra Pradesh. Ind J Med Microbiol. 2015;33(1)68-72.

Available

from:

[Article:http://www.ijmm.org/text.asp?

2015/33/1/68/148381][Crossref]

07. Vivek K, Vinod K, Ashok KY, Sreenivasa I, Ashish B, Navneet S, Ritesh A, Sanjay J, Vivekanand J. Scrub typhus is an underrecognized cause of acute febrile illness with acute kidney injury in India. PLoS Negl Trop Dis. $2014 ; 8(1)$ e2605.

doi:

[Article:https://doi.org/10.1371/journal.pntd.000260 5][Crossref]

08. Laskar AR, Suri S, Acharya AS. Scrub typhusRe-emerging public health problem in India. J Comm Dis. 2015;47(3)19-25.

[Crossref]

09. Kedareshwar PS, Narvencar, Savio R, Ramnath PN, Lydia D, Amit D, Marina V, Gomes E. Scrub typhus in patients reporting with acute febrile illness at a tertiary health care institution in Goa. Ind J Med Res. 2012;136(6)1020-1024.

Available from:

[Article:http://www.ijmr.org.in/text.asp? 2012/136/6/1020/106863][Crossref]

10. Prakash J, Abraham OC, Mathai E. Evaluation of tests for serological diagnosis of scrub typhus. Trop Doct. 2006;36(4)212-213. doi:[Article:https://doi.org/10.1258/0049475 06778604715][Crossref] 
11. Mathai E, Rolain JM, Verghese GM, Abraham OC, Mathai $D$, Mathai $M$, et al. Outbreak of scrub typhus in southern India during the cooler months. Ann N Y Acad Sci. 2003;990(1)359364.

doi: [Article:https://doi.org/10.1111/j.17496632.2003.tb07391.x][Crossref]

12. Kumar M, Krishnamurthy $S$, Delhikumar CG, Narayanan P, Biswal N, Srinivasan S. Scrub typhus in children at a tertiary hospital in southern India- Clinical profile and complications. J Infect Publ HIth. 2012;5(1)8288.

doi:

[Article:https://doi.org/10.1016/j.jiph.2011.11.001] [Crossref]

13. Borkakoty B, Jakharia A, Biswas D, Mahanta J. Co-infection of scrub typhus and leptospirosis in patients with pyrexia of unknown origin in Longding district of Arunachal Pradesh in 2013. Ind J Med Microbiol. 2016;34(1)88-91.

Available from: [Article:http://www.ijmm.org/text.asp? 2016/34/1/88/174116][Crossref]

14. Silpasakorn S, Waywa D, Hoontrakul S, Suttinont C, Losuwanaluk K, Suputtamongkol Y. Performance of SD bioline Tsutsugamushi assays for the diagnosis of scrub typhus in Thailand. J Med Assoc Thai. 2012; 95(2)18-22. [Crossref]
15. Jacob SM, Sekkizhar G, Kanagasabai S, Gopal P, Gopal T, Elumalai S. Seroprevalence and clinical manifestations of scrub typhus infection in Chennai city- A cross-sectional study. Int J HIth All Sci. 2018;7(3)201-203.

Available from:[Article:http://www.ijhas.in/text.asp? 2018/7/3/201/237268][Crossref]

16. Lee KD, Moon C, Oh WS, Sohn KM, Kim BN. Diagnosis of scrub typhus: Introduction of the immunochromatographic test in Korea. Korean J Intern Med. 2014;29(2)253-255.

doi:

[Article:https://doi.org/10.3904/kjim.2014.29.2.253] [Crossref]

17. Kim YJ, Park S, Premaratna R, Selvaraj S, Park SJ, Kim S, et al. Clinical evaluation of rapid diagnostic test kit for scrub typhus with improved performance. J Korean Med Sci. 2016;31(8)1190-1196.

doi:[Article:https://doi.org/10.3346/jkms.2016.

31.8.1190][Crossref]

18. Rao PN, Eijk AM, Choubey S, Ali SZ, Dash A, Barla $P$, et al. Dengue, chikungunya, and scrub typhus are important etiologies of non-malarial febrile illness in Rourkela, Odisha, India. BMC Infect Dis. 2019;19(1)572-577.

doi: [Article:https://doi.org/10.1186/s12879-0194161-6][Crossref] 